Check for updates

Cite this: RSC Adv., 2019, 9, 23964

\title{
Manganese-cerium mixed oxides supported on rice husk based activated carbon with high sulfur tolerance for low-temperature selective catalytic reduction of nitrogen oxides with ammonia $\uparrow$
}

\begin{abstract}
Yun Shu, (D) Fan Zhang and Hongchang Wang
A rice husk-derived activated carbon supported manganese-cerium mixed oxide catalyst ( $\mathrm{Mn}-\mathrm{Ce} / \mathrm{RAC}$ ) was prepared by an impregnation method and tested for the selective catalytic reduction of nitrogen oxides with ammonia ( $\mathrm{NH}_{3}-\mathrm{SCR}$ ). $5 \mathrm{wt} \% \mathrm{Mn}-\mathrm{Ce} / \mathrm{RAC}$ catalyst showed the highest activity, yielding nearly $100 \% \mathrm{NO}_{x}$ conversion and $\mathrm{N}_{2}$ selectivity at $240{ }^{\circ} \mathrm{C}$ at a space velocity of $30000 \mathrm{~h}^{-1}$. Compared with commercial activated carbon supported manganese-cerium mixed oxide catalyst ( $\mathrm{Mn}-\mathrm{Ce} / \mathrm{SAC}$ ), a higher SCR performance with good $\mathrm{SO}_{2}$ tolerance could be observed in the tested temperature range over the $\mathrm{Mn}-\mathrm{Ce} / \mathrm{RAC}$ catalyst. The characterization results revealed that the $\mathrm{Mn}-\mathrm{Ce} / \mathrm{RAC}$ catalyst had a higher $\mathrm{Mn}^{4+} / \mathrm{Mn}^{3+}$ ratio, amount of chemisorbed oxygen and more Brønsted acid sites than the $\mathrm{Mn-}$ $\mathrm{Ce} / \mathrm{SAC}$ catalyst. The XRD analysis indicated that $\mathrm{Mn}-\mathrm{Ce}$ oxides were highly dispersed on the RAC support. These properties of $\mathrm{Mn}-\mathrm{Ce} / \mathrm{RAC}$ assisted the SCR reaction. Moreover, in situ DRIFTS results demonstrated that sulfate species formation on $\mathrm{Mn}-\mathrm{Ce} / \mathrm{RAC}$ was much less in the presence of $\mathrm{SO}_{2}$ than that of $\mathrm{Mn}-\mathrm{Ce} / \mathrm{SAC}$, which might be ascribed to the reduced alkalinity of the catalyst by the presence of

$\mathrm{SiO}_{2}$ in RAC.
\end{abstract}

Received 24th May 2019

Accepted 26th July 2019

DOI: 10.1039/c9ra03937f

rsc.li/rsc-advances

\section{Introduction}

Nitrogen oxides $\left(\mathrm{NO}_{x}\right)$ emitted from power plants and diesel engines are major air pollutants, which can result in acid rain, photochemical smog, and ozone destruction. Selective catalytic reduction (SCR) with $\mathrm{NH}_{3}$ is the most widely used technology for post- $\mathrm{NO}_{x}$ removal, and $\mathrm{V}_{2} \mathrm{O}_{5}-\mathrm{WO}_{3}\left(\mathrm{MoO}_{3}\right) / \mathrm{TiO}_{2}$ has been commonly used with high catalytic activity at $300-400{ }^{\circ} \mathrm{C} .{ }^{1-3}$ However, several shortcomings of $\mathrm{V}_{2} \mathrm{O}_{5}$-based catalysts still need to be addressed, including the toxicity of vanadium, $\mathrm{SO}_{2}$ oxidation to $\mathrm{SO}_{3}$, and the poor low-temperature SCR activity. Therefore, it is extremely desirable to develop environmentfriendly non-vanadium-based catalysts with high catalytic activity, and high $\mathrm{SO}_{2}$-tolerance within low-temperature regions.

On the basis of the good low-temperature activity and their inherent environmentally benign characters, Mn-based

State Key Laboratory of Environmental Criteria and Risk Assessment, Chinese Research Academy of Environmental Sciences, Beijing 100012, China. E-mail: shuyun@craes.org.cn; Tel: +861084934516

$\dagger$ Electronic supplementary information (ESI) available: Characteristics of raw biomasses, Raman spectra of different samples, Si 2p XPS spectra of Mn-Ce/RAC and Mn-Ce/SAC catalysts and FT-IR spectra of Mn-Ce/RAC and $\mathrm{Mn}-\mathrm{Ce} / \mathrm{SAC}$ catalysts before and after pretreatment with a flow of $800 \mathrm{ppm}$ NO-800 ppm $\mathrm{NH}_{3}-3 \% \mathrm{O}_{2}-300$ ppm $\mathrm{SO}_{2}-10$ vol\% $\mathrm{H}_{2} \mathrm{O}$ are shown. See DOI: 10.1039/c9ra03937f catalysts have been widely developed for SCR of NO with $\mathrm{NH}_{3} \cdot{ }^{4-6}$ Unfortunately, $\mathrm{Mn}$-based catalysts are very sensitive to the presence of $\mathrm{SO}_{2}$ in the feed gas, which can induce a severe deactivation. ${ }^{7,8}$ Based on its high oxygen storage capacity and unique redox properties, ceria has been investigated extensively, which is usually introduced as a promoter for enhancing $\mathrm{SO}_{2}$ resistance of $\mathrm{Mn}$-based catalysts due to the interaction between $\mathrm{MnO}_{x}$ and $\mathrm{CeO}_{x}$, leading to the inhibition of formation of ammonium sulfates and $\mathrm{MnSO}_{4}$ on the catalyst surface. ${ }^{9-14}$ Fan et al. ${ }^{13}$ reported that a strong synergistic effect existed in Mn-Ce/CeAPSO-34 catalyst, which showed outstanding $\mathrm{SO}_{2}$ tolerance and $\mathrm{H}_{2} \mathrm{O}$ resistance. Jin et al. ${ }^{14}$ studied the role of ceria in the improved resistance for a Cemodified $\mathrm{Mn} / \mathrm{TiO}_{2}$ catalyst. In their investigation, the introduction of Ce lessened the sulfation of the main active phase $\left(\mathrm{MnO}_{x}\right)$ during low-temperature SCR processes in the presence of $\mathrm{SO}_{2}$. Nevertheless, it is still necessary to further improve the resistance of $\mathrm{SO}_{2}$ for $\mathrm{Mn}$-Ce binary metal oxide catalysts.

Generally, supports play an important role in SCR reaction. Proper supports not only can provide a huge surface to disperse the active components and prevent the formation of large crystalline particles but can also affect the sulfur tolerance. Carbon materials (i.e., activated carbon (AC), ${ }^{15}$ activated coke ${ }^{16}$ and carbon fiber ${ }^{17}$ ) are widely used as supports for $\mathrm{NH}_{3}$-SCR reaction and exhibit a high $\mathrm{NO}_{x}$ removal efficiency at low 
temperatures $\left(100-250{ }^{\circ} \mathrm{C}\right)$. Zhu et al. reported that activated carbon supported vanadium oxide catalyst showed high activity in presence of $\mathrm{SO}_{2}$ at $180-250{ }^{\circ} \mathrm{C}$ due to formation of $\mathrm{SO}_{4}{ }^{2-} \cdot{ }^{15,18}$ In addition, $\mathrm{SiO}_{2}$ was proposed to be a structural promoter to enhance the $\mathrm{SO}_{2}$ resistance of catalyst. ${ }^{19-21}$ Liu et al.${ }^{19}$ observed that the addition of $\mathrm{SiO}_{2}$ improved SCR performance of $\mathrm{Ce} / \mathrm{TiO}_{2}$ catalyst. They reported that the introduction of $\mathrm{SiO}_{2}$ could weaken the alkalinity over the surface of $\mathrm{Ce} / \mathrm{TiO}_{2}-\mathrm{SiO}_{2}$ catalyst, which resulted in sulfate not easily accumulating on the surface of the $\mathrm{Ce} / \mathrm{TiO}_{2}-\mathrm{SiO}_{2}$ in comparison with the $\mathrm{Ce} / \mathrm{TiO}_{2}$. From the research by Kobayashi et al.,$^{20}$ the $\mathrm{SO}_{2}$ tolerance was found to be more excellent over vanadia loaded on $\mathrm{TiO}_{2}-\mathrm{SiO}_{2}$ than over that on pure $\mathrm{TiO}_{2}$, which was ascribed to the increased acidity of the former. However, it should be noted that the $\mathrm{SiO}_{2}$ precursors usually used were commercially made alkoxysilane compounds such as tetraethylorthosilicate, colloidal silica and tetramethylorthosilicate. Nakashima et $a .^{22}$ reported that acute exposure to tetraethylorthosilicate can lead to death. Thus, there is a need to find a safer and less expensive silica source.

Rice husk is a major agriculture by-product in several parts of Asia, mainly in China and India. This biomass waste possesses unique properties, such as high $\mathrm{SiO}_{2}$ content, high porosity and large external surface area. ${ }^{23}$ In addition, biomass has proven to be a promising type of raw material for producing activated carbon with high adsorption capacity. ${ }^{24,25}$ These properties make the rice husk an idea biomass waste for use as an alternative silica source, a catalyst or a catalyst support for pollutant removal. Inspired by those mentioned points, it is speculated that rice husk might be a good option to be used as precursor for producing activated carbon, which could be used as supports for SCR processes and exhibit a good $\mathrm{SO}_{2}$ tolerance at low temperatures.

In this paper, activated carbon was prepared from rice husk and subsequently impregnated with $\mathrm{MnO}_{x}$ and $\mathrm{CeO}_{x}$ for SCR of $\mathrm{NO}$ with $\mathrm{NH}_{3}$. The attempt was to develop low-temperature $\mathrm{deNO}_{x}$ catalyst having good $\mathrm{SO}_{2}$ tolerance. For comparison purposes, the catalytic activity of commercial activated carbon catalyst with the same active composition was investigated under the same working conditions.

\section{Experimental}

The rice husk of the most widely grown variety of rice in China was chosen for this study. After receiving, it was thoroughly washed to remove impurities and then dried at $110{ }^{\circ} \mathrm{C}$ for $24 \mathrm{~h}$. After drying, the sample was cut in uniform lengths of $\leq 5 \mathrm{~mm}$. The proximate and elemental analysis of raw rice husk was in Table S1 in ESI. $\dagger$ It could be found that the raw sample showed a higher volatile and low $\mathrm{N}$ and $\mathrm{S}$ content, and the heating value was about $15 \mathrm{MJ} \mathrm{kg}^{-1}$. It was an ideal renewable energy resource, with minor environmental pollution.

\section{Chemically activated carbon}

A known mass of rice husk was immersed in $100 \mathrm{ml}$ of activating agent which comprised of $\mathrm{H}_{3} \mathrm{PO}_{4}$ and $\mathrm{H}_{2} \mathrm{O}$. The mixture was continuously stirred for $2 \mathrm{~h}$, and then it was oven dried at
$120{ }^{\circ} \mathrm{C}$ for $48 \mathrm{~h}$. The activation of the mixture was performed in a fixed bed reactor. The reactor was heated to $800^{\circ} \mathrm{C}$ at a heating rate of $5{ }^{\circ} \mathrm{C} \mathrm{min}^{-1}$ and maintained for $2 \mathrm{~h}$ in $\mathrm{N}_{2}\left(200 \mathrm{ml} \mathrm{min}^{-1}\right)$. Then, the sample was cooled down to room temperature under an $\mathrm{N}_{2}$ atmosphere. The resulting activated carbon sample was washed with $\mathrm{NaOH}$ solution, followed by distilled water until the wash water reached a $\mathrm{pH}$ of 6-7 to remove residual $\mathrm{PO}_{4}{ }^{3-}$. The final activated carbon sample was dried and sieved to obtain a particle size range of 40-60 mesh.

\section{Catalyst}

The chemically activated carbon was supported with $\mathrm{Mn}$ and Ce using impregnation methods, where $\mathrm{Mn}$ and Ce nitrates $(\mathrm{Mn} / \mathrm{Ce}$ molar ratio, $2: 1$ ) were dissolved in deionized water, and certain amount of the chemically activated carbon was added. The mixture of metal nitrates and carbon was heated and continuously stirred for $2 \mathrm{~h}$. Then, the sample was dried for $12 \mathrm{~h}$ at $110{ }^{\circ} \mathrm{C}$ in a drying oven. After drying, the sample was calcined for $5 \mathrm{~h}$ at $500{ }^{\circ} \mathrm{C}$ in tubular furnace with heating rate of $10{ }^{\circ} \mathrm{C} \min ^{-1}$ under $\mathrm{N}_{2}$ atmosphere. Finally, the sample was cooled down to room temperature with protection of $\mathrm{N}_{2}$. MnCe/activated carbon (with commercial activated carbon as the support) was also prepared through the same method for comparison. The commercial activated carbon made from sawdust was purchased from Sinopharm Chemical Reagent limited corporation. The resulting catalyst is denoted as $\mathrm{Mn}-\mathrm{Ce} /$ $\mathrm{XAC}(\mathrm{X}$ represents the initial raw material for the activated carbon preparation, $\mathrm{X}=\mathrm{R}$ and $\mathrm{S}$ ). For example, $\mathrm{Mn}-\mathrm{Ce} / \mathrm{RAC}$ and $\mathrm{Mn}-\mathrm{Ce} / \mathrm{SAC}$ indicate the rice husk-based activated carbon supported $\mathrm{Mn}-\mathrm{Ce}$ catalyst and the sawdust-based activated carbon supported Mn-Ce catalyst, respectively.

\section{SCR activity measurements}

$\mathrm{NH}_{3}$-SCR activity measurements were carried out in a fixed-bed quartz flow reactor (i.d. $9 \mathrm{~mm}$ ) containing $0.5 \mathrm{~g}$ of catalyst. The reactor was electrically heated, which was described in detail in our previous study. ${ }^{26}$ The typical composition of the reactant gas

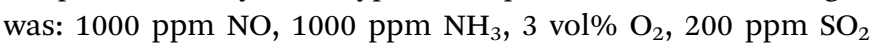
(when needed), and $\mathrm{N}_{2}$ as the balance gas. The total flow rate was $500 \mathrm{ml} \mathrm{min}^{-1}$ (refers to $1 \mathrm{~atm}$ and $298 \mathrm{~K}$ ) which corresponded to a gas hourly space velocity (GHSV) of $30000 \mathrm{~h}^{-1}$. Before entering the reactor, the reactant gases were mixed in a mixing tubing, but $\mathrm{NH}_{3}$ was fed directly into the reactor by passing the mixing tubing to avoid possible reaction between $\mathrm{SO}_{2}$ and $\mathrm{NH}_{3}$ before the catalyst bed. Water vapor was generated by passing $\mathrm{N}_{2}$ through a gas-wash bottle containing deionized water. The tubings of the reactor system were heated to prevent the formation and deposition of ammonium sulfate/bisulfate and ammonium nitrate. The $\mathrm{NO}, \mathrm{NO}_{2}, \mathrm{NH}_{3}, \mathrm{SO}_{2}$ and $\mathrm{N}_{2} \mathrm{O}$ concentrations were measured online with a Fourier transform infrared (FTIR) analyzer system (GASMET DX-4000) produced by Gasmet Technologies, Inc. in Finland. The $\mathrm{O}_{2}$ concentrations were measured via an electrochemical gas analyser (Testo 340). The reaction system was kept for $1 \mathrm{~h}$ at each reaction temperature to reach a steady state before the analysis of the product 
was performed. The $\mathrm{NO}_{x}$ conversion and $\mathrm{N}_{2}$ selectivity were calculated as follows:

$$
\mathrm{NO}_{x} \text { conversion }=\left(1-\frac{\left[\mathrm{NO}_{x}\right]_{\text {out }}}{\left[\mathrm{NO}_{x}\right]_{\text {in }}}\right) \times 100 \%
$$

$$
\begin{aligned}
& \mathrm{N}_{2} \text { selectivity } \\
& \quad=\frac{\left[\mathrm{NO}_{x}\right]_{\text {in }}+\left[\mathrm{NH}_{3}\right]_{\text {in }}-\left[\mathrm{NO}_{x}\right]_{\text {out }}-\left[\mathrm{NH}_{3}\right]_{\text {out }}-2\left[\mathrm{~N}_{2} \mathrm{O}\right]_{\text {out }}}{\left[\mathrm{NO}_{x}\right]_{\text {in }}+\left[\mathrm{NH}_{3}\right]_{\text {in }}-\left[\mathrm{NO}_{x}\right]_{\text {out }}-\left[\mathrm{NH}_{3}\right]_{\text {out }}} \times 100
\end{aligned}
$$

where $\left[\mathrm{NO}_{x}\right]=[\mathrm{NO}]+\left[\mathrm{NO}_{2}\right],\left[\mathrm{NO}_{x}\right]_{\text {in }}$ and $\left[\mathrm{NO}_{x}\right]_{\text {out }}$ were the concentrations of $\mathrm{NO}_{x}$ at the inlet and outlet of the tube, respectively. In order to confirm that the decrease of $\mathrm{NO}_{x}$ was not caused by the adsorption of $\mathrm{NO}_{x}$, at the beginning of each experiment, the catalyst was purged with the reactant gas until there was no difference between the inlet and the outlet gas.

\section{Catalyst characterization}

The specific surface areas of the catalysts were measured by nitrogen adsorption using the Brunauer-Emmett-Teller (BET) method (Quadrasorb SI). Powder X-ray diffraction (XRD) measurements were carried out on a Rigaku D/MAX-2400 X-ray diffractometer with $\mathrm{Cu} \mathrm{K} \alpha$ radiation. X-ray photoelectron spectroscopy (XPS) was implemented on a surface analysis system (Thermal ESCALAB 250) using $\mathrm{Al} \mathrm{K} \alpha$ radiation. The $\mathrm{C} 1 \mathrm{~s}$ line at $284.6 \mathrm{eV}$ was considered as a reference for the binding energy calibration. The peak fitting was carried out using a XPSPEAK41 processing program. Temperature-programmed reduction $\left(\mathrm{H}_{2}-\right.$ TPR) was performed on a ChemBET PULSAR TPR/TPD instrument. Prior to TPR experiments, the catalysts were pretreated at $400{ }^{\circ} \mathrm{C}$ for $2 \mathrm{~h}$ under helium flow, then cooled down to room temperature. Finally, the reactor temperature was raised to $700{ }^{\circ} \mathrm{C}$ at a constant heating rate of $10{ }^{\circ} \mathrm{C} \mathrm{min}^{-1}$ in a flow of $\mathrm{H}_{2}$ (5 vol\%)/He. Temperature-programmed desorption (TPD) experiments of $\mathrm{NH}_{3}$ and $\mathrm{SO}_{2}$ were performed on the same ChemBET PULSAR TPR/TPD instrument. The experiment consisted of four stages: (i) degasification of the sample in $\mathrm{He}$ at $400{ }^{\circ} \mathrm{C}$ for $2 \mathrm{~h}$, (ii) adsorption of $\mathrm{NH}_{3}\left(300 \mathrm{ppm} \mathrm{SO}_{2}+3 \% \mathrm{O}_{2}\right)$ at room temperature for $1 \mathrm{~h}$, (iii) isothermal desorption under $\mathrm{He}$ until no $\mathrm{NH}_{3} \quad\left(\mathrm{SO}_{2}\right)$ was detected, and (iv) temperatureprogrammed desorption under $\mathrm{He}$ at $10{ }^{\circ} \mathrm{C} \mathrm{min}^{-1}$ to $500{ }^{\circ} \mathrm{C}$ or $800{ }^{\circ} \mathrm{C}$. In situ diffuse reflectance infrared Fourier transform spectroscopy (in situ DRIFTS) was performed on a FTIR spectrometer (Bruker Vertex 70) equipped with a high sensitivity MCT detector cooled by liquid $\mathrm{N}_{2}$. An approximately $12 \mathrm{mg}$ sample was finely ground and pressed into a self-supported wafer. Mass flow controllers and a sample temperature controller were used to simulate the real reaction conditions. Prior to each experiment, the wafer was heated to $350{ }^{\circ} \mathrm{C}$ in $\mathrm{N}_{2}$ (99.999\%) for $1 \mathrm{~h}$ and then cooled down to the desired reaction temperature. The background spectrum was collected in flowing $\mathrm{N}_{2}$ and automatically subtracted from the sample spectrum. The reaction conditions were controlled as follows: 500

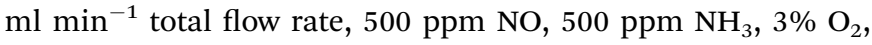
(100 ppm $\mathrm{SO}_{2}$ when used) and $\mathrm{N}_{2}$ balance. All spectra were recorded by accumulating 100 scans with a resolution of $4 \mathrm{~cm}^{-1}$.

\section{Results and discussion}

\section{Effect of the loading amounts of Mn-Ce on SCR activity}

Fig. 1 displays $\mathrm{NO}_{x}$ conversion and $\mathrm{N}_{2}$ selectivity at various temperatures for the $\mathrm{Mn}-\mathrm{Ce} / \mathrm{RAC}$-catalyzed $\mathrm{NH}_{3}$-SCR reaction with varying $\mathrm{Mn}$-Ce loadings. The SCR activity of the RAC were quite low in the whole temperature range, with $\mathrm{NO}_{x}$ conversions less than 9\%. After Mn-Ce oxide species were loaded onto the $\mathrm{RAC}$, the $\mathrm{NO}_{x}$ conversion of $\mathrm{Mn}-\mathrm{Ce} / \mathrm{RAC}$ was greater than $80 \%$ at $240{ }^{\circ} \mathrm{C}$. It demonstrated that $\mathrm{Mn}-\mathrm{Ce}$ based catalyst could exhibited high SCR activity at relatively low temperature range as the literatures reported. ${ }^{27}$ As the Mn-Ce loading increased from 1 wt $\%$ to 5 wt $\%$, the $\mathrm{NO}_{x}$ conversion improved gradually. At a Mn-Ce loading of $5 \mathrm{wt} \%$, for example, the $\mathrm{NO}_{x}$ conversion was $99.4 \%$ at $240{ }^{\circ} \mathrm{C}$. Further increase of the Mn-Ce loading from $5 \mathrm{wt} \%$ to $10 \mathrm{wt} \%$ led to certain decline in $\mathrm{NO}_{x}$ conversion at both low and high temperatures, which might be ascribed to aggregation of active component on the surface of RAC. ${ }^{27,28}$ All of the catalysts exhibited high $\mathrm{N}_{2}$ selectivity ( $\left.>95 \%\right)$ across tested temperature ranges (as shown in inset of Fig. 1). The formation of $\mathrm{N}_{2} \mathrm{O}$ was less than $5 \mathrm{ppm}$. Since the $5 \mathrm{wt} \% \mathrm{Mn}-\mathrm{Ce} / \mathrm{RAC}$ catalyst showed the highest SCR activity, all of the Mn-Ce/RAC catalysts that appeared below had a Mn-Ce loading of $5 \mathrm{wt} \%$.

\section{Comparison with $\mathrm{Mn}-\mathrm{Ce} / \mathrm{SAC}$ catalyst}

In order to test the effect of the support, the $\mathrm{NO}_{x}$ conversion and $\mathrm{N}_{2}$ selectivity over Mn-Ce/RAC and Mn-Ce/SAC catalysts were compared, and the results are shown in Fig. 2. The active component loading and the experimental conditions were the same. The Mn-Ce/RAC catalyst showed a higher SCR activity in the whole temperature range than $\mathrm{Mn}-\mathrm{Ce} / \mathrm{SAC}$, together with much better $\mathrm{N}_{2}$ selectivity. It indicated that the activity of $\mathrm{Mn}-$ $\mathrm{Ce} / \mathrm{RAC}$ catalyst was significantly improved in comparison with $\mathrm{Mn}-\mathrm{Ce} / \mathrm{SAC}$ catalyst by taking the RAC as support.

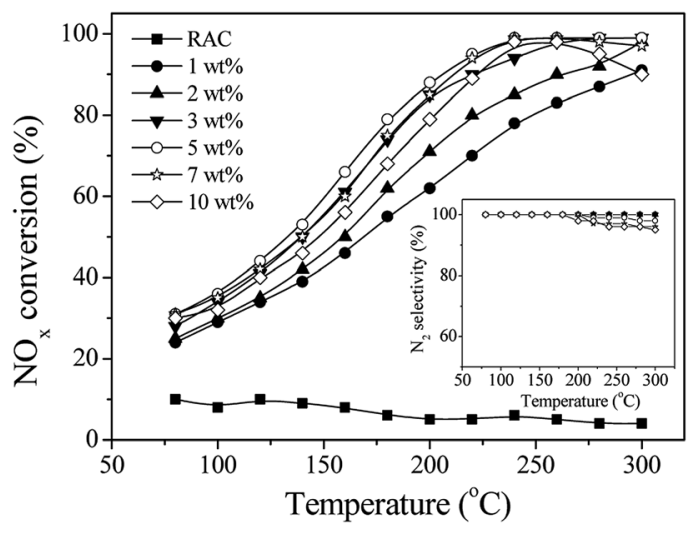

Fig. $1 \mathrm{NO}_{x}$ conversion during the SCR reaction over $\mathrm{Mn}-\mathrm{Ce} / \mathrm{RAC}$ catalysts with different $\mathrm{Mn}-\mathrm{Ce}$ loadings. Reaction conditions: 800 ppm NO, 800 ppm NH $3,3 \% \mathrm{O}_{2}, \mathrm{~N}_{2}$ as balance gas, and GHSV = $30000 \mathrm{~h}^{-1}$. Inset: $\mathrm{N}_{2}$ selectivity during the SCR reaction. 


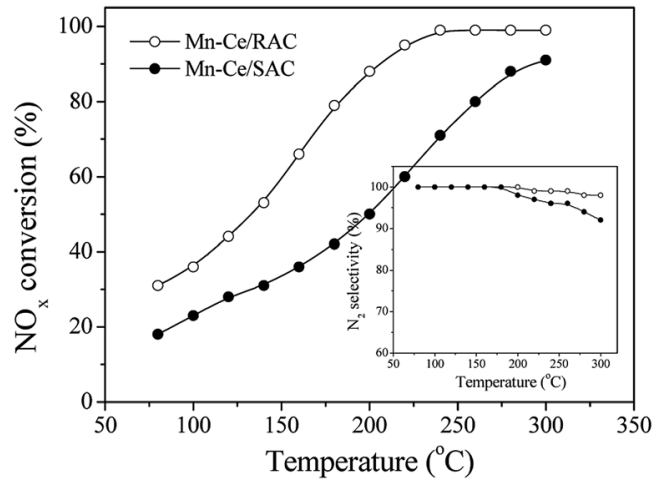

Fig. $2 \mathrm{NO}_{x}$ conversion during the SCR reaction over $\mathrm{Mn}-\mathrm{Ce} / \mathrm{RAC}$ and $\mathrm{Mn}-\mathrm{Ce} / \mathrm{SAC}$ catalysts. Reaction conditions: $800 \mathrm{ppm}$ NO, $800 \mathrm{ppm}$ $\mathrm{NH}_{3}, 3 \% \mathrm{O}_{2}, \mathrm{~N}_{2}$ as balance gas, and GHSV $=30000 \mathrm{~h}^{-1}$. Inset: $\mathrm{N}_{2}$ selectivity during the SCR reaction.

\section{Effects of $\mathrm{SO}_{2}$ and $\mathrm{H}_{2} \mathrm{O}$}

The emissions of $\mathrm{SO}_{2}$ and $\mathrm{H}_{2} \mathrm{O}$ are unavoidable in exhaust and flue gases, and the investigation of the impact of $\mathrm{SO}_{2}$ and $\mathrm{H}_{2} \mathrm{O}$ on the SCR activity of catalysts is therefore important. Fig. 3A shows the SCR activity over the Mn-Ce/RAC and Mn-Ce/SAC catalysts in the presence of $10 \mathrm{vol} \% \mathrm{H}_{2} \mathrm{O}$ at $240{ }^{\circ} \mathrm{C}$. When the steam was added to the reaction system, the $\mathrm{NO}_{x}$ conversions of the two catalysts were little changed within $10 \mathrm{~h}$. This suggested that individual $\mathrm{H}_{2} \mathrm{O}$ in the feed gas at $240{ }^{\circ} \mathrm{C}$ had nearly no influence on the SCR activity of Mn-Ce/RAC and Mn-Ce/SAC catalysts.

Fig. 3B depicts the $\mathrm{SO}_{2}$ tolerance tests of the catalysts in the presence of $300 \mathrm{ppm} \mathrm{SO} \mathrm{S}_{2}$ at $240{ }^{\circ} \mathrm{C}$. The $\mathrm{NO}_{x}$ conversion over Mn-Ce/RAC decreased slightly after $\mathrm{SO}_{2}$ was added to the reaction gas, and it then reached a steady state. After switching $\mathrm{SO}_{2}$ off, the activity was restored. In contrast, in the case of Mn$\mathrm{Ce} / \mathrm{SAC}$, the introduction of $\mathrm{SO}_{2}$ induced a dramatic drop from $80 \%$ to $63 \%$ after $10 \mathrm{~h}$, and the $\mathrm{NO}_{x}$ conversion of $\mathrm{Mn}-\mathrm{Ce} / \mathrm{SAC}$ only returned to $70 \%$, far from the initial level. These results demonstrated that the $\mathrm{Mn}-\mathrm{Ce} / \mathrm{RAC}$ catalyst presented

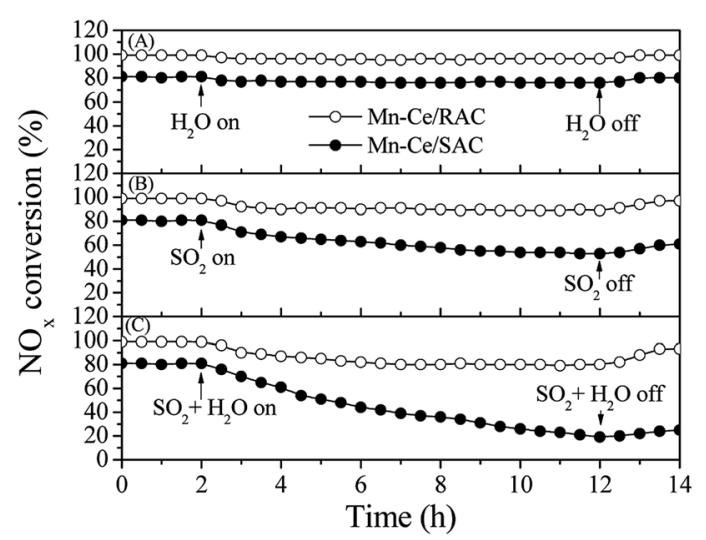

Fig. 3 (A) $\mathrm{H}_{2} \mathrm{O}$ resistance, (B) $\mathrm{SO}_{2}$ tolerance, (C) $\mathrm{SO}_{2}$ and $\mathrm{H}_{2} \mathrm{O}$ synergetic effect study of the catalysts at $240{ }^{\circ} \mathrm{C}$. Reaction conditions: 800 ppm NO, 800 ppm NH 3,300 ppm SO (when used), 10 vol\% $\mathrm{H}_{2} \mathrm{O}$ (when used), $3 \% \mathrm{O}_{2}, \mathrm{~N}_{2}$ as balance gas, and GHSV $=30000 \mathrm{~h}^{-1}$. advantages in $\mathrm{SO}_{2}$ tolerance over the $\mathrm{Mn}-\mathrm{Ce} / \mathrm{SAC}$ catalyst. According to literatures, ${ }^{8,18}$ the deactivation of the catalyst caused by $\mathrm{SO}_{2}$ was related with the formation of $\left(\mathrm{NH}_{4}\right)_{2} \mathrm{SO}_{4}$ or $\mathrm{NH}_{4} \mathrm{HSO}_{4}$, which deposited on the surface of catalyst and blocked the partial active sites.

The combined impact of $\mathrm{SO}_{2}$ and $\mathrm{H}_{2} \mathrm{O}$ on SCR activity were also investigated (Fig. 3C). The introduction of $\mathrm{SO}_{2}$ and $\mathrm{H}_{2} \mathrm{O}$ induced a $18 \%$ decrease in the $\mathrm{NO}_{x}$ conversion over $\mathrm{Mn}-\mathrm{Ce} /$ RAC. But the $\mathrm{NO}_{x}$ conversion gradually recovered to $93 \%$ after shutting off the supply of $\mathrm{SO}_{2}$ and $\mathrm{H}_{2} \mathrm{O}$. However, the conversion of $\mathrm{NO}_{x}$ on $\mathrm{Mn}-\mathrm{Ce} / \mathrm{SAC}$ decreased quickly from $80 \%$ to $35 \%$ and barely recovered even though $\mathrm{SO}_{2}+\mathrm{H}_{2} \mathrm{O}$ was eliminated. It indicated that there was a synergistic inhibition effect between $\mathrm{SO}_{2}$ and $\mathrm{H}_{2} \mathrm{O}$ in the SCR reaction. When $\mathrm{SO}_{2}$ and $\mathrm{H}_{2} \mathrm{O}$ were added simultaneously, water would make the formation of the ammonium sulfate species more rapid, resulting in a dramatic decrease in $\mathrm{NO}_{x}$ conversion. ${ }^{29}$ It could be concluded from the above results that Mn-Ce/RAC were highly sulfur-tolerant and water-resistant, and RAC presented a positive role in the sulfur and water tolerance of the catalyst.

\section{Characterization of supports and catalysts}

BET. The BET surface, pore volume and pore size of the catalysts are summarized in Table 1 . It could be seen that the surface area and total pore volume of the catalysts decreased after the impregnation process, which might be resulted from the clogging of pores by the impregnated metallic oxides. ${ }^{30,31}$ $\mathrm{Mn}-\mathrm{Ce} / \mathrm{RAC}$ showed a smaller loss of BET surface area than $\mathrm{Mn}-\mathrm{Ce} / \mathrm{SAC}$ after loading with the Mn and Ce oxides. In addition, compared with the Mn-Ce/SAC, the Mn-Ce/RAC had lower surface area and total pore volume, but a higher activity towards $\mathrm{NO}_{x}$ reduction. This agreed with previous findings that the catalytic activity was more dependent on surface chemistry than surface area. ${ }^{32}$

XRD. The XRD patterns of various samples are displayed in Fig. 4. A broad diffraction peak was observed at $\sim 24.5^{\circ}$ for all the samples, which indicated that the activated carbon sample had a low graphitization structure. ${ }^{33}$ After introducing Mn and Ce oxides, no visible phase of manganese oxides and ceria could be observed on Mn-Ce/RAC, but the $\mathrm{Mn}_{2} \mathrm{O}_{3}$ (JCPDS 06-0540), $\mathrm{MnO}_{2}$ (JCPDS 30-0820) and cubic $\mathrm{CeO}_{2}$ (JCPDS 43-1002) phases could be detected on $\mathrm{Mn}-\mathrm{Ce} / \mathrm{SAC}$. These results indicated that the active components $\mathrm{Mn}$ and Ce oxides were highly dispersed on the surface of the RAC support. In combination with XPS results in the following section, the reason for the high dispersion of Mn and Ce oxides on RAC might be that a large amount of surface oxygen groups on RAC could accelerate the

Table 1 Physical properties of various samples

\begin{tabular}{llll}
\hline Sample & $\begin{array}{l}\text { BET surface } \\
\text { area }\left(\mathrm{m}^{2} \mathrm{~g}^{-1}\right)\end{array}$ & $\begin{array}{l}\text { Total pore volume } \\
\left(\mathrm{ml} \mathrm{g}^{-1}\right)\end{array}$ & $\begin{array}{l}\text { Average pore } \\
\text { diameter }(\mathrm{nm})\end{array}$ \\
\hline RAC & 291.6 & 0.18 & 2.79 \\
Mn-Ce/RAC & 249.5 & 0.13 & 3.87 \\
SAC & 382.9 & 0.24 & 2.14 \\
Mn-Ce/SAC & 265.8 & 0.14 & 2.51
\end{tabular}




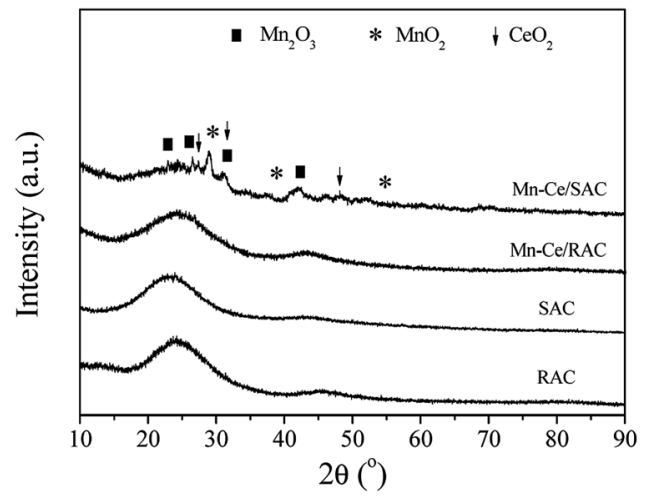

Fig. 4 The XRD patterns of various samples.

diffusion of $\mathrm{Mn}$ and Ce ions into the inner pores of RAC by the interaction between $\mathrm{Mn}$ and Ce precursors and surface oxygen groups, resulting in an improvement of the dispersion of $\mathrm{Mn}$ and Ce oxides. $^{34}$ The highly dispersed active phases were demonstrated to improve the surface properties of catalysts, resulting in an enhancement of the catalytic activity, ${ }^{16}$ which was in accordance with the SCR activity results. Fig. S1† compares the Raman spectra of RAC and SAC based catalysts. Three characteristic peaks at about $1350 \mathrm{~cm}^{-1}$ (D band), $1590 \mathrm{~cm}^{-1}$ (G band) and $2700 \mathrm{~cm}^{-1}$ (2D band) in the graphitized structures were observed in the Raman spectrum of all the samples. ${ }^{35}$

XPS. The catalysts were further analyzed using XPS to identify the surface nature and content of the active species. Surface atomic contents of $\mathrm{Mn}, \mathrm{Ce}, \mathrm{O}$ and $\mathrm{Si}$ are summarized in Table 2, and photoelectron spectra of $\mathrm{Mn} 2 \mathrm{p}$, Ce $3 \mathrm{~d}$ and $\mathrm{O} 1 \mathrm{~s}$ levels are displayed in Fig. 5. As listed in Table 2, the $\mathrm{Mn}$ and $\mathrm{Ce}$ concentrations on Mn-Ce/RAC were higher than those on Mn$\mathrm{Ce} / \mathrm{SAC}$. And the results of Fig. 4 indicated that the enrichment of Mn and Ce on the surface of the Mn-Ce/RAC catalyst did not lead to the crystallization in the catalyst. These implied that $\mathrm{Mn}-\mathrm{Ce} / \mathrm{RAC}$ had a higher ability to disperse Mn and Ce oxides than $\mathrm{Mn}-\mathrm{Ce} / \mathrm{SAC}$. In addition, on the Mn-Ce/SAC catalyst no obvious $\mathrm{Si} 2 \mathrm{p}$ band was detected, while an evident band attributed to $\mathrm{Si} 2 \mathrm{p}$ was observed on the Mn-Ce/RAC catalyst (Fig. S2 in ESI $\dagger$ ). The binding energies of this Si 2p was $103.8 \mathrm{eV}$, which was consistent with the $\mathrm{Si}(\mathrm{Iv})$ oxidation state and assigned to the $\mathrm{SiO}_{2}$ species. ${ }^{36}$

In Fig. $5 \mathrm{~A}$, two main peaks of $\mathrm{Mn} 2 \mathrm{p}_{3 / 2}$ and $\mathrm{Mn} 2 \mathrm{p}_{1 / 2}$ were observed in the binding energy range from $636 \mathrm{eV}$ to $660 \mathrm{eV}$. The asymmetric $\mathrm{Mn} 2 \mathrm{p}_{3 / 2}$ peak confirmed the existence of mixed valence of manganese states. Thus, the Mn oxide states were further analyzed by deconvolution and curve fitting procedures.

Table 2 XPS results of $\mathrm{Mn}-\mathrm{Ce} / \mathrm{RAC}$ and $\mathrm{Mn}-\mathrm{Ce} / \mathrm{SAC}$ catalysts

\begin{tabular}{lrlllllll}
\hline \multicolumn{1}{c}{$\begin{array}{l}\text { Surface atomic } \\
\text { content (\%) }\end{array}$} & & & & \\
nyyllyst & $\mathrm{Mn}$ & $\mathrm{Ce}$ & $\mathrm{O}$ & $\mathrm{Si}$ & $\mathrm{Mn}^{4+} / \mathrm{Mn}^{3+}$ & $\begin{array}{l}\mathrm{Ce}^{3+} /\left(\mathrm{Ce}^{3+}+\mathrm{Ce}^{4+}\right)(\%) \\
\text { Catalys }\end{array}$ & $\begin{array}{l}\mathrm{O}_{\alpha} /\left(\mathrm{O}_{\alpha}+\right. \\
\left.\mathrm{O}_{\beta}\right)(\%)\end{array}$ \\
\hline Mn-Ce/RAC & 11.2 & 4.2 & 48.5 & 5.1 & 3.35 & 40.5 & 48.5 \\
Mn-Ce/SAC & 8.7 & 3.8 & 44.2 & 0.9 & 2.07 & 20.9 & 32.6
\end{tabular}
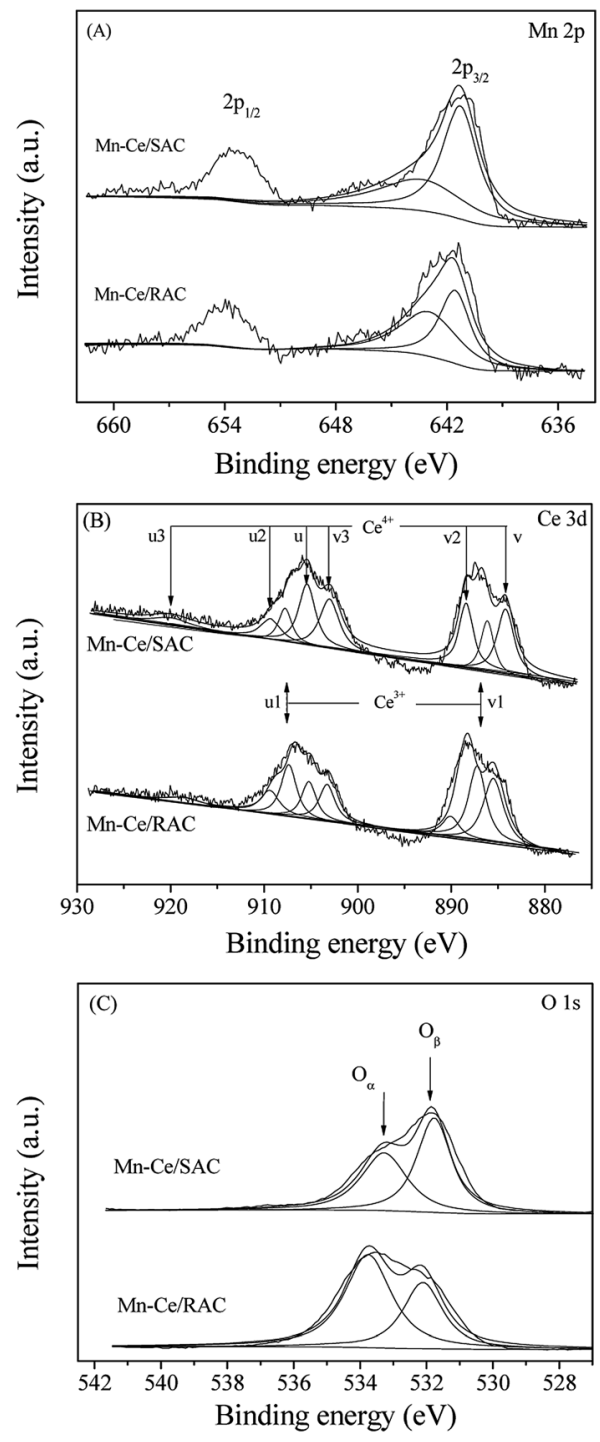

Fig. 5 (A) Mn 2p, (B) Ce 3d and (C) O 1s XPS spectra of Mn-Ce/RAC and $\mathrm{Mn}-\mathrm{Ce} / \mathrm{SAC}$ catalysts.

The binding energy for $\mathrm{Mn}^{4+}$ is approximately $643.1 \mathrm{eV}$, whereas the binding energy for $\mathrm{Mn}^{3+}$ is approximately $641.7 \mathrm{eV} \cdot{ }^{37,38} \mathrm{As}$ observed in Table 2, the $\mathrm{Mn}^{4+} / \mathrm{Mn}^{3+}$ ratio for $\mathrm{Mn}-\mathrm{Ce} / \mathrm{RAC}$ was higher than Mn-Ce/SAC. This suggested a higher average valence state of $\mathrm{Mn}$ ions on the surface of Mn-Ce/RAC than that on $\mathrm{Mn}-\mathrm{Ce} / \mathrm{SAC}$. It is well known that $\mathrm{Mn}^{4+}$ species is more active than $\mathrm{Mn}^{3+}$ species, and the $\mathrm{Mn}^{4+}$ can enhance the $\mathrm{NO}$ to $\mathrm{NO}_{2}$ oxidation and as a result of this promoting the SCR reaction through the "fast SCR" pathway. Therefore, Mn-Ce/RAC exhibited higher $\mathrm{NO}_{x}$ conversion than Mn-Ce/SAC, as shown in Fig. 2.

The Ce 3d XPS spectra of Mn-Ce/RAC and Mn-Ce/SAC catalysts (Fig. 5B) were fitted into two bands ( $\mathrm{u}$ and v). The bands labeled $\mathrm{u} 1$ and $\mathrm{v} 1$ represent the $3 \mathrm{~d}^{10} 4 \mathrm{f}^{1}$ initial electronic state, corresponding to $\mathrm{Ce}^{3+}$, whereas the peaks labeled $\mathrm{u}, \mathrm{u} 2$, $\mathrm{u} 3, \mathrm{v}, \mathrm{v} 2$ and v3 represent the $3 \mathrm{~d}^{10} 4 \mathrm{f}^{0}$ state of $\mathrm{Ce}^{4+}$ ions. ${ }^{39}$ The intensities of $\mathrm{Ce}^{3+}$ characteristic peaks over $\mathrm{Mn}-\mathrm{Ce} / \mathrm{RAC}$ were more intense than those over $\mathrm{Mn}-\mathrm{Ce} / \mathrm{SAC}$. The $\mathrm{Ce}^{3+}$ ratio, 
calculated by $\mathrm{Ce}^{3+} /\left(\mathrm{Ce}^{3+}+\mathrm{Ce}^{4+}\right)$, of $\mathrm{Mn}-\mathrm{Ce} / \mathrm{RAC}(40.5 \%)$ was higher than that of Mn-Ce/SAC (20.9\%), as listed in Table 2. It indicated that Ce was in a partially reduced state on the surface of the Mn-Ce/RAC catalyst, which might be attributed to the presence of $\mathrm{SiO}_{2}$ in RAC. ${ }^{19}$ Some researchers have reported that the presence of $\mathrm{Ce}^{3+}$ could induce charge imbalance, more vacancies and unsaturated chemical bonds on the catalyst surface, and thus lead to the increase of surface chemisorbed oxygen. $^{40,41}$

Fig. $5 \mathrm{C}$ reveals the fitted $\mathrm{O} 1 \mathrm{~s}$ peaks for lattice oxygen $\mathrm{O}^{2-}$ at 529.5-529.8 eV (denoted as $\mathrm{O}_{\beta}$ ) and chemisorbed oxygen at 531.0-531.4 eV (denoted as $\mathrm{O}_{\alpha}$ ), such as $\mathrm{O}_{2}{ }^{2-}$ and $\mathrm{O}^{-}$belonging to defect-oxide or hydroxyl-like group. ${ }^{42}$ As shown in Table 2, the $\mathrm{O}_{\alpha}$ of $\mathrm{Mn}-\mathrm{Ce} / \mathrm{RAC}(48.5 \%)$ calculated by $\mathrm{O}_{\alpha} /\left(\mathrm{O}_{\alpha}+\mathrm{O}_{\beta}\right)$ was much higher than that of Mn-Ce/SAC (32.6\%). Surface chemisorbed oxygen $\left(\mathrm{O}_{\alpha}\right)$ has been reported to be more active than lattice oxygen $\left(\mathrm{O}_{\beta}\right)$ due to its higher mobility and plays an important role in oxidation reactions. ${ }^{43}$ Therefore, the higher $\mathrm{O}_{\alpha}$ on $\mathrm{Mn}-$ Ce/RAC was beneficial for the NO oxidation to $\mathrm{NO}_{2}$ in the SCR reaction, and thereby facilitated the "fast SCR" reaction and enhanced deNO $\mathrm{N}_{x}$ efficiency. On the other hand, a larger amount of surface hydroxyl groups could act as Brønsted acid sites to enhance the $\mathrm{NH}_{3}$ adsorption. ${ }^{2,3}$ The enhancement of $\mathrm{NH}_{3}$ adsorption over the $\mathrm{Mn}-\mathrm{Ce} / \mathrm{RAC}$ catalyst would be discussed later.

$\mathbf{H}_{2}$-TPR and $\mathbf{N H}_{3}$-TPD. The redox properties of the $\mathrm{Mn}-\mathrm{Ce} /$ RAC and Mn-Ce/SAC catalysts are examined using $\mathrm{H}_{2}$-TPR experiment (as shown in Fig. 6). It could be seen that there was one broad peak on these two catalysts. This suggested that the reducible metal oxide species might exist in a mixed valence. As for $\mathrm{Mn}-\mathrm{Ce} / \mathrm{SAC}$ catalyst, the TPR profile was fitted into two reduction peaks: the peak at $452{ }^{\circ} \mathrm{C}$ was ascribed to the reduction of $\mathrm{MnO}_{2}$ to $\mathrm{Mn}_{2} \mathrm{O}_{3}$, while the peak at $497{ }^{\circ} \mathrm{C}$ was attributed to the reduction of $\mathrm{Mn}_{2} \mathrm{O}_{3}$ to $\mathrm{MnO}$ and surface cerium oxides. ${ }^{44}$ In terms of $\mathrm{Mn}-\mathrm{Ce} / \mathrm{RAC}$ catalyst, the TPR profile was also fitted into two peaks corresponding to the reduction of $\mathrm{Mn}$ and Ce oxide species. Compared with $\mathrm{Mn}-\mathrm{Ce} / \mathrm{SAC}$, the reduction peaks of $\mathrm{Mn}-\mathrm{Ce} / \mathrm{RAC}$ shifted toward a lower temperature region. As reported in the literature, ${ }^{5}$ the lower reduction temperature for the catalyst indicated better redox characteristics. The redox character for the Mn-Ce/RAC catalyst seemed to be better than the $\mathrm{Mn}-\mathrm{Ce} / \mathrm{SAC}$ catalyst.

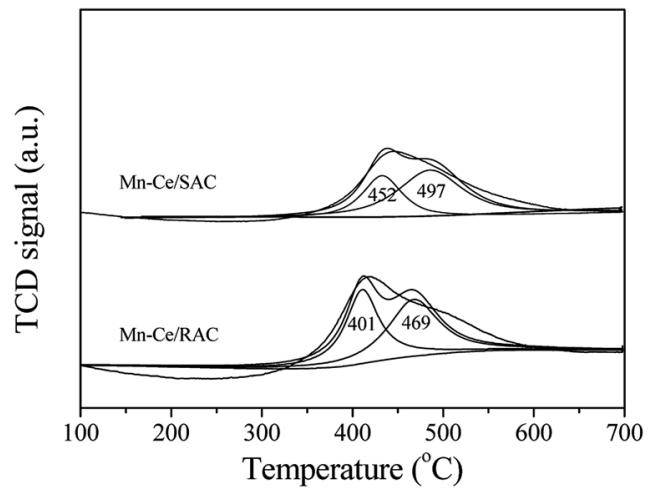

Fig. $6 \mathrm{H}_{2}$-TPR profiles of $\mathrm{Mn}-\mathrm{Ce} / \mathrm{RAC}$ and $\mathrm{Mn}-\mathrm{Ce} / \mathrm{SAC}$ catalysts.

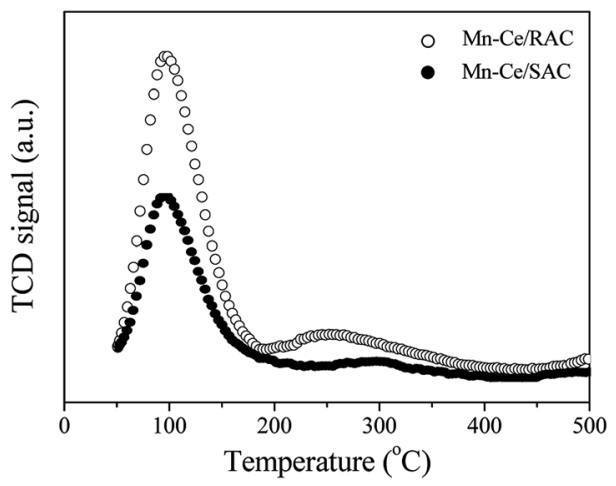

Fig. $7 \mathrm{NH}_{3}-\mathrm{TPD}$ profiles of $\mathrm{Mn}-\mathrm{Ce} / \mathrm{RAC}$ and $\mathrm{Mn}-\mathrm{Ce} / \mathrm{SAC}$ catalysts.

The $\mathrm{NH}_{3}$-TPD profiles of the $\mathrm{Mn}-\mathrm{Ce} / \mathrm{RAC}$ and $\mathrm{Mn}-\mathrm{Ce} / \mathrm{SAC}$ catalysts are shown in Fig. 7. The desorption peaks of these two catalysts appeared primarily in the temperature range of $50-150{ }^{\circ} \mathrm{C}$ (weak acid sites) and $220-360{ }^{\circ} \mathrm{C}$ (medium acid sites), respectively. ${ }^{45}$ It was found that the intensities of desorption peaks (weak and medium acid sites) on the surface of the Mn$\mathrm{Ce} / \mathrm{RAC}$ catalyst were obviously higher than those on the Mn$\mathrm{Ce} / \mathrm{SAC}$ catalyst, especially for the desorption peak belonging to weak acid sites. This result implied that the Mn-Ce/RAC catalyst had more acidic sites than the Mn-Ce/SAC catalyst. Many research showed that the surface acidity played a critical role in SCR reaction. ${ }^{4-6}$ Consequently, the increased acidic sites might represent one of the most important reasons for the higher catalytic activity of the Mn-Ce/RAC catalyst than that of the Mn$\mathrm{Ce} / \mathrm{SAC}$ catalyst.

$\mathrm{SO}_{2}$-TPD. $\mathrm{SO}_{2}$-TPD experiments over $\mathrm{Mn}-\mathrm{Ce} / \mathrm{RAC}$ and $\mathrm{Mn}-$ $\mathrm{Ce} / \mathrm{SAC}$ catalysts pretreated with a $\mathrm{SO}_{2}-\mathrm{O}_{2}$ coexisting feed gas were performed to determine adsorption/desorption characteristics of $\mathrm{SO}_{2}$ over the catalysts. The catalysts for the TPD experiments were treated with a flow of $300 \mathrm{ppm} \mathrm{SO}_{2}+3 \% \mathrm{O}_{2}$ at $240{ }^{\circ} \mathrm{C}$, as shown in Fig. 8. One major $\mathrm{SO}_{2}$ desorption peak was found for Mn-Ce/RAC and Mn-Ce/SAC at around $460{ }^{\circ} \mathrm{C}$, which could be ascribed to the decomposition of sulfate species on the surface of the catalyst. ${ }^{\mathbf{4 6 , 4 7}}$ The $\mathrm{SO}_{2}$ desorption peak for the $\mathrm{Mn}$ $\mathrm{Ce} / \mathrm{RAC}$ catalyst was obviously smaller than that for the $\mathrm{Mn}-\mathrm{Ce} /$ SAC catalyst, demonstrating that the $\mathrm{Mn}-\mathrm{Ce} / \mathrm{RAC}$ was more $\mathrm{SO}_{2}$ resistance and with less $\mathrm{SO}_{2}$ adsorption on its surface. It was

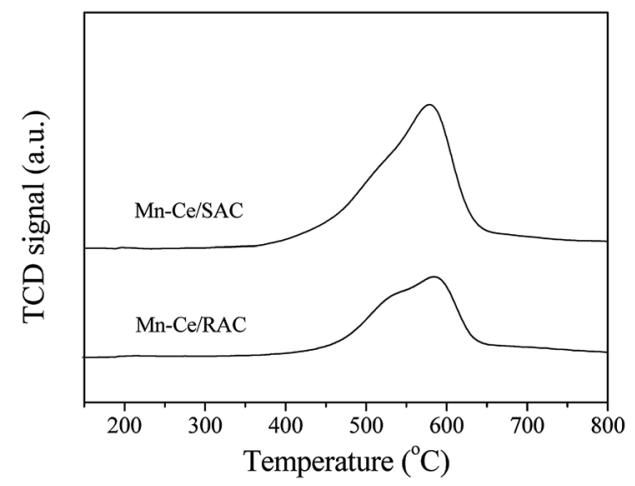

Fig. $8 \mathrm{SO}_{2}$-TPD profiles of $\mathrm{Mn}-\mathrm{Ce} / \mathrm{RAC}$ and $\mathrm{Mn}-\mathrm{Ce} / \mathrm{SAC}$ catalysts. 
found by Liu et al. ${ }^{19}$ that the addition of $\mathrm{SiO}_{2}$ to SCR catalyst could weaken the alkalinity of the catalyst, which resulted in sulfate species not easily adsorbing on the surface of the catalyst. Hence, the presence of $\mathrm{SiO}_{2}$ in RAC support reduced the alkalinity on the surface of Mn-Ce/RAC catalyst, thereafter suppressing the formation of sulfate species. This might represent a significant factor for the high activity of the $\mathrm{Mn}-\mathrm{Ce} /$ RAC in the presence of $\mathrm{SO}_{2}+\mathrm{H}_{2} \mathrm{O}$ (as shown in Fig. 3).

In situ DRIFTS study. To further distinguish between the different acid types (Lewis or Brønsted acid sites on the catalyst surface), in situ DRIFTS experiments were employed to study the $\mathrm{NH}_{3}$ adsorption/desorption behavior of the catalysts. The DRIFTS spectra of $\mathrm{NH}_{3}$ over Mn-Ce/RAC and Mn-Ce/SAC catalysts at $240{ }^{\circ} \mathrm{C}$ are shown in Fig. 9. After samples were exposed to $\mathrm{NH}_{3}$ in $\mathrm{N}_{2}$ for $60 \mathrm{~min}$ and purge with $\mathrm{N}_{2}$, the bands at $1685 \mathrm{~cm}^{-1}$ and $1410 \mathrm{~cm}^{-1}$ were assigned to the symmetric and asymmetric bending vibrations of $\mathrm{NH}_{4}{ }^{+}$species on Brønsted acid sites, ${ }^{\mathbf{4 8 , 4 9}}$ while the bands at $1602 \mathrm{~cm}^{-1}, 1245$ and $1180 \mathrm{~cm}^{-1}$ were attributed to symmetric and asymmetric bending vibrations of the $\mathrm{N}-\mathrm{H}$ bonds in $\mathrm{NH}_{3}$ coordinated to Lewis acid sites. ${ }^{\mathbf{4 8 , 5 0}}$ Obviously, the stronger $\mathrm{NH}_{4}{ }^{+}\left(1671\right.$ and $\left.1428 \mathrm{~cm}^{-1}\right)$ bands were observed on Mn-Ce/RAC, despite its low surface area, than those on Mn-Ce/SAC, indicating that the Brønsted acid sites was enhanced on the $\mathrm{Mn}-\mathrm{Ce} / \mathrm{RAC}$ catalyst. Some researchers showed that the presence of $\mathrm{SiO}_{2}$ could enhance surface acidity of the catalyst, especially the number of Brønsted acid sites. ${ }^{19,51}$ Thus, the enhanced Brønsted acid sites of Mn-Ce/RAC, compared with that of $\mathrm{Mn}-\mathrm{Ce} / \mathrm{SAC}$, should be ascribed to the presence of $\mathrm{SiO}_{2}$ in RAC support.

To understand deactivation mechanism of Mn-Ce/RAC and $\mathrm{Mn}-\mathrm{Ce} / \mathrm{SAC}$ by $\mathrm{SO}_{2}$ for the $\mathrm{NH}_{3}$-SCR, the DRIFTS spectra of catalysts in a flow of $\mathrm{NH}_{3}+\mathrm{NO}+\mathrm{O}_{2}$ before and after the addition of $100 \mathrm{ppm} \mathrm{SO}_{2}$ at $240{ }^{\circ} \mathrm{C}$ were recorded. Fig. 10A shows the DRIFTS spectra of $\mathrm{Mn}-\mathrm{Ce} / \mathrm{SAC}$ catalyst. When a mixture of $\mathrm{NH}_{3}$, $\mathrm{NO}, \mathrm{O}_{2}$ and $\mathrm{N}_{2}$ were flowed over the catalyst for $30 \mathrm{~min}$, the bands ascribed to ionic $\mathrm{NH}_{4}^{+}\left(1670 \mathrm{~cm}^{-1}\right)$ and coordinated $\mathrm{NH}_{3}$ (1245 $\mathrm{cm}^{-1}$ ) showed up. ${ }^{48,49}$ The band at $1258 \mathrm{~cm}^{-1}$ might be attributed to nitrate species. ${ }^{52}$ After $\mathrm{SO}_{2}$ was flowed for $5 \mathrm{~min}$, the intensity of the band at $1258 \mathrm{~cm}^{-1}$ due to nitrate species increased obviously, and its position moved to high wavenumber at $1262 \mathrm{~cm}^{-1}$. According to the reported literature, ${ }^{53} \mathrm{we}$

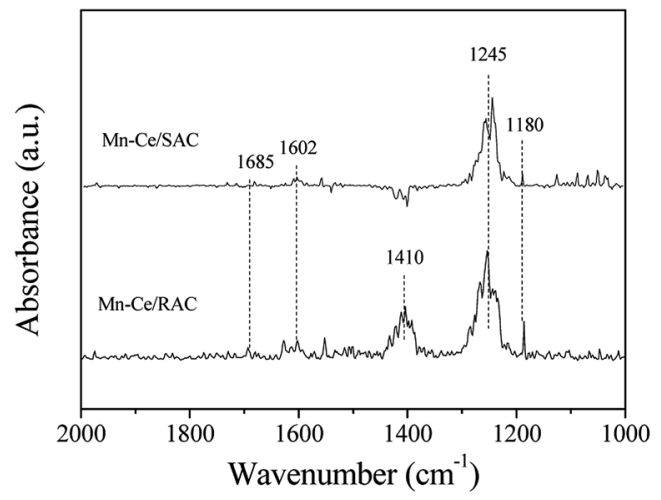

Fig. 9 DRIFTS spectra of $\mathrm{NH}_{3}$ adsorption over $\mathrm{Mn}-\mathrm{Ce} / \mathrm{RAC}$ and $\mathrm{Mn}-$ $\mathrm{Ce} / \mathrm{SAC}$ catalysts at $240^{\circ} \mathrm{C}$.
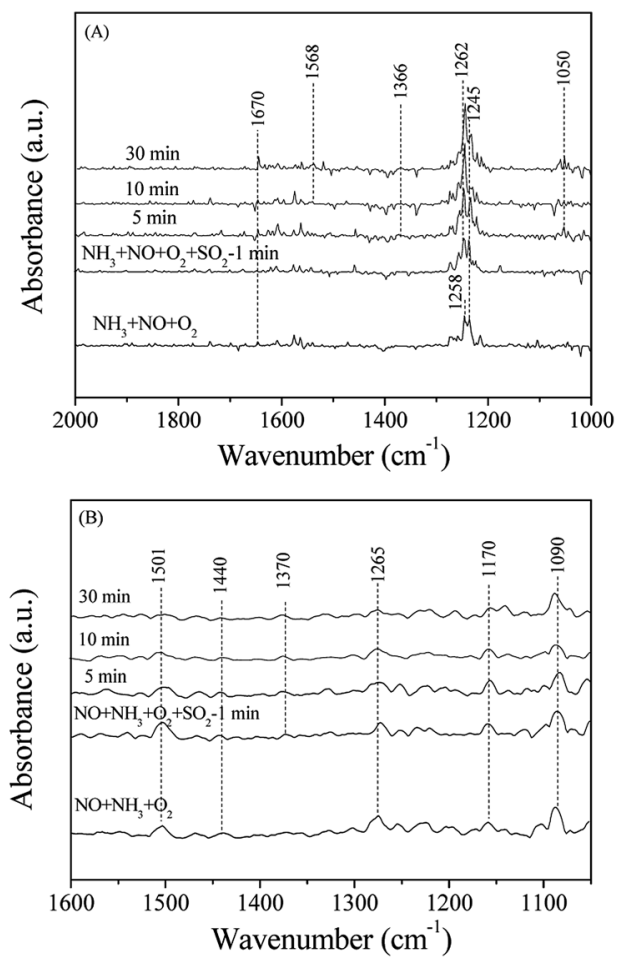

Fig. 10 DRIFTS spectra of $M n-C e / S A C$ (A) and $M n-C e / R A C$ (B) catalysts in a flow of $\mathrm{NH}_{3}+\mathrm{NO}+\mathrm{O}_{2}$ before and after the addition of $100 \mathrm{ppm} \mathrm{SO}$ at $240{ }^{\circ} \mathrm{C}$

could assign the bands at 1262 (overlap band) and $1366 \mathrm{~cm}^{-1}$ to the deposited sulfate species. The band at $1050 \mathrm{~cm}^{-1}$ might be attributed to the perturbation of sulfate species ( $v s \mathrm{~S}-\mathrm{O}$ ) through reaction with $\mathrm{NH}_{3}$ to form ammonium sulfate. ${ }^{50}$ Moreover, $\mathrm{HSO}_{4}{ }^{-}\left(1568 \mathrm{~cm}^{-1}\right)^{54}$ was also found to increase with $\mathrm{SO}_{2}$ exposure time verifying the formation of $\mathrm{NH}_{4} \mathrm{HSO}_{4}$. These results suggested that the formation of $\left(\mathrm{NH}_{4}\right)_{2} \mathrm{SO}_{4}$ and $\mathrm{NH}_{4} \mathrm{HSO}_{4}$ should be responsible for the deactivated observed for the Mn-Ce/SAC catalyst (as shown in Fig. 3), which was in agreement with a previous report. ${ }^{15,18}$ From Fig. 10B, when the SCR gases were directed into the reactor for $30 \mathrm{~min}$, the adsorption peaks of $\mathrm{NH}_{4}^{+}\left(1440 \mathrm{~cm}^{-1}\right)$ and coordinated $\mathrm{NH}_{3}$ (1265 and $1170 \mathrm{~cm}^{-1}$ ) appeared on the surface of the $\mathrm{Mn}-\mathrm{Ce} /$ RAC catalyst. Anionic nitrosyl $\mathrm{NO}^{-}$species have been observed by some researchers giving rise to absorption in the region of $1200-1000 \mathrm{~cm}^{-1} \cdot{ }^{55,56}$ So the band at $1090 \mathrm{~cm}^{-1}$ could be assigned to anionic nitrosyl $\mathrm{NO}^{-}$species. Additional adsorbed species was also found, namely cis- $\mathrm{N}_{2} \mathrm{O}_{2}{ }^{2-}\left(1501 \mathrm{~cm}^{-1}\right) .{ }^{57}$ After the addition of $\mathrm{SO}_{2}$, no obvious change was observed on $\mathrm{Mn}-\mathrm{Ce} / \mathrm{RAC}$, except for that a weak adsorption peak linked to sulfate species $\left(1370 \mathrm{~cm}^{-1}\right)$ was detected after $5 \mathrm{~min}$. These results demonstrated that the $\mathrm{Mn}-\mathrm{Ce} / \mathrm{SAC}$ catalyst exhibited significant adsorption of $\mathrm{SO}_{2}$ which leads to deactivation caused by $\left(\mathrm{NH}_{4}\right)_{2} \mathrm{SO}_{4}$ and $\mathrm{NH}_{4} \mathrm{HSO}_{4}$ formation on the surface of the catalyst. Conversely, the $\mathrm{Mn}-\mathrm{Ce} / \mathrm{RAC}$ catalyst resulted in very minor formation of sulfate species after $\mathrm{SO}_{2}$ exposure, demonstrating an improved $\mathrm{SO}_{2}$ resistance of the catalyst. This was consistent with the Fourier transform infrared spectroscopy (FT-IR) results (Fig. S3 in ESI $\dagger$ ) that there was little ammonium- 
sulfate salts deposited on the surface of the Mn-Ce/RAC catalyst compared to that of the $\mathrm{Mn}-\mathrm{Ce} / \mathrm{SAC}$ catalyst during the pretreatment with a flow of $\mathrm{NO}-\mathrm{NH}_{3}-\mathrm{O}_{2}-\mathrm{SO}_{2}-\mathrm{H}_{2} \mathrm{O}$.

\section{Conclusions}

This work has evaluated rice husk-derived activated carbon impregnated with the $\mathrm{Mn}-\mathrm{Ce}$ as a potential catalyst in the $\mathrm{NH}_{3}$ SCR. Mn-Ce loading enhanced the SCR performance of RAC, and $5 \mathrm{wt} \%$ was the optimum mass ratio for the Mn-Ce/RAC catalyst. In comparison with the Mn-Ce/SAC, the Mn-Ce/RAC had a high SCR performance and a good tolerance to $\mathrm{SO}_{2}$. The XRD analysis indicated that Mn-Ce was more dispersed on the surface of RAC support than SAC support. The high $\mathrm{Mn}^{4+}$ / $\mathrm{Mn}^{3+}$ ratios, chemisorbed oxygen content and more Brønsted acid sites as well as the enhanced redox activity of the $\mathrm{Mn}-\mathrm{Ce} /$ RAC catalyst improved its $\mathrm{NH}_{3}$-SCR activity. In situ DRIFTS results demonstrated that sulfate formation was suppressed on the surface of the RAC support, which might be the most significant reason that Mn-Ce/RAC maintained a high SCR activity in the presence of $\mathrm{SO}_{2}$. This study demonstrated that the rice husk might be a potential material for use as a low temperature SCR catalytic support instead of the commercial activated carbon.

\section{Conflicts of interest}

There are no conflicts to declare.

\section{Acknowledgements}

This work was supported by the National Key Research and Development Program of China (2017YFC0213000) and the National Natural Science Foundation of China (No. 21507119).

\section{References}

1 L. J. Alemany, F. Berti, G. Busca, G. Ramis, et al., Appl. Catal., B, 1996, 10, 299-311.

2 G. Busca, L. Lietti, G. Ramis and F. Berti, Appl. Catal., B, 1998, 18, 1-36.

3 M. Kobayashi and K. Miyoshi, Appl. Catal., B, 2007, 72, 253261.

4 X. L. Tang, J. M. Hao, W. G. Xu and J. H. Li, Catal. Commun., 2007, 8, 329-334.

5 K. J. Lee, P. A. Kumar, M. S. Maqbool, et al., Appl. Catal., B, 2013, 142, 705-717.

6 W. Tian, H. Yang, X. Fan and X. Zhang, J. Hazard. Mater., 2011, 188, 105-109.

7 W. S. Kijlstra, M. Biervliet, E. K. Poels and A. Bliek, Appl. Catal., B, 1998, 16, 327-337.

8 J. A. Loiland and R. F. Lobo, J. Catal., 2014, 311, 412-423.

9 G. Qi and R. T. Yang, Chem. Commun., 2003, 7, 848-849.

10 Z. Liu, Y. Yi, S. Zhang, T. Zhu, J. Zhu and J. Wang, Catal. Today, 2013, 216, 76-81.

11 Y. Wei, Y. Sun, W. Su and J. Liu, $R S C A d v .$, 2015, 5, 2623126235.
12 X. Chen, P. Wang, P. Fang, et al., Fuel Process. Technol., 2017, 167, 221-228.

13 Y. Fan, W. Ling, B. Huang, et al., J. Ind. Eng. Chem., 2017, 56, 108-119.

14 R. Jin, Y. Liu, Y. Wang, et al., Appl. Catal., B, 2014, 148, 582588.

15 Z. P. Zhu, Z. Y. Liu, S. Liu and H. X. Niu, Appl. Catal., B, 2001, 30, 267-276.

16 P. Li, Q. Liu and Z. Liu, Chem. Eng. J., 2012, 181, 169-173.

17 P. Lu, C. Li, G. Zeng, L. He, D. Peng, H. Cui, S. Li and Y. Zhai, Appl. Catal., B, 2010, 96, 157-161.

18 Z. P. Zhu, H. X. Niu, Z. Y. Liu and S. Liu, J. Catal., 2000, 195, 268-278.

19 C. Liu, L. Chen, J. H. Li and J. M. Hao, Environ. Sci. Technol., 2012, 46, 6182-6189.

20 M. Kobayashi, R. Kuma, S. Masaki and N. Sugishima, Appl. Catal., B, 2005, 60, 173-179.

21 Z. Liu, J. Tabora and R. Davis, J. Catal., 1994, 149, 117-126.

22 H. Nakashima, K. Omae, T. Takebayashi, C. Ishizuka and T. Uemura, J. Occup. Health, 1998, 40, 270-275.

23 N. Soltani, A. Bahrami, M. I. Pech-Canul and L. A. Gonzàlez, Chem. Eng. J., 2015, 264, 899-935.

24 T. C. Chandra, M. M. Mirna, Y. Sudaryanto and S. Ismadji, Chem. Eng. J., 2007, 127, 121-129.

25 K. Nuithitikul, S. Srikhun and S. Hirunpraditkoon, Bioresour. Technol., 2010, 207, 426-429.

26 Y. Shu, H. Wang, J. Zhu and F. Zhang, Chem. Res. Chin. Univ., 2014, 30, 1005-1010.

27 W. Xu, Y. Yu, C. Zhang and H. He, Catal. Commun., 2008, 3, 1453-1457.

28 B. Huang, R. Huang, D. Jin and D. Ye, Catal. Today, 2007, 126, 279-283.

29 R. Gao, D. Zhang, X. Liu, L. Shi, P. Maitarad and H. Li, Catal. Sci. Technol., 2013, 3, 191-199.

30 D. K. Pappas, T. Boningari, P. Boolchand and P. G. Smirniotis, J. Catal., 2016, 334, 1-13.

31 Q. Yan, Y. Nie, R. Yang, Y. Cui and Q. Wang, Appl. Catal., A, 2017, 538, 37-50.

32 J. Muñiz, G. Marbán and A. B. Fuertes, Appl. Catal., B, 2000, 27, 27-36.

33 Y. Liao, L. Jia, R. Chen, M. Sakuraib and H. Kameyamab, Appl. Catal., A, 2016, 522, 32-39.

34 Y. Xue, Y. Guo, Z. Zhang, G. Lu, et al., Appl. Surf. Sci., 2008, 255, 2591-2595.

35 N. Apostolescu, B. Geiger, K. Hizbullah, et al., Appl. Catal., B, 2006, 62, 104-114.

36 T. Pınar and Y. Sevil, Asia-Pac. J. Chem. Eng., 2019, 14, 22622276.

37 D. A. Pena, B. S. Uphade and P. G. Smirniotis, J. Catal., 2004, 221, 421-431.

38 P. R. Ettireddy, N. Ettireddy, S. Mamedov, P. Boolchand and P. G. Smirniotis, Appl. Catal., B, 2007, 76, 123-134.

39 M. Romeo, K. Bak, J. E. Fallah, F. L. Normand and L. Hilaire, Surf. Interface Anal., 1993, 20, 508-512.

40 B. Reddy, M. Khan, A. Yamada, Y. Kobayashi and T. Loridant, J. Phys. Chem. B, 2003, 107, 5162-5167. 
41 S. Yang, X. Zhu, W. P. Jiang, Z. P. Chen and Z. X. Wang, Appl. Surf. Sci., 2006, 252, 8499-8505.

42 J. C. Dupin, D. Gonbeau, P. Vinatier and A. Levasseur, Phys. Chem. Chem. Phys., 2000, 2, 1319-1324.

43 J. Fang, X. Bi, D. Si, Z. Jiang and W. Huang, Appl. Surf. Sci., 2007, 253, 8952-8961.

44 P. Li, Y. Xin, Q. Li, Z. Wang, Z. Zhang and L. Zheng, Environ. Sci. Technol., 2012, 46, 9600-9605.

45 V. Vishwanathan, J. Ki-Won, K. Jae-Woo and R. Hyun-Seog, Appl. Catal., A, 2004, 276, 251-255.

46 J. H. Li, Y. Q. Zhu, R. Ke and J. M. Hao, Appl. Catal., B, 2008, 208, 202-213.

47 Y. X. Chen, Y. Jiang, W. Z. Li, R. C. Jin, S. Z. Tang and W. B. Hu, Catal. Today, 1999, 50, 39-47.

48 Z. B. Wu, B. Q. Jiang, Y. Liu, H. Q. Wang and R. B. Jin, Environ. Sci. Technol., 2007, 41, 5812-5817.
49 G. Ramis, Y. Li, G. Busca, M. Turco, E. Kotur and R. J. Willey, J. Catal., 1995, 157, 523-535.

50 Z. Tao, Q. Feng and H. Chang, Catal. Commun., 2017, 100, 117-120.

51 P. Yue, L. Cai and Z. Xue, Appl. Catal., B, 2013, 140, 276-282. 52 G. Qi, R. T. Yang and R. Chang, Appl. Catal., B, 2004, 51, 93106.

53 B. Q. Jiang, Z. B. Wu, Y. Liu, S. C. Lee and W. K. Ho, J. Phys. Chem. C, 2010, 114, 4961-4966.

54 S. M. Muhammad, K. P. Anil and P. H. Heon, Appl. Catal., B, 2014, 152, 28-37.

55 J. Liam, Y. Qing and L. Wan, Appl. Catal., B, 2017, 206, 203215.

56 K. Hadjiivanov and H. Knözinger, Phys. Chem. Chem. Phys., 2000, 2, 2803-2806.

57 M. Kantcheva, J. Catal., 2001, 204, 479-494. 